\title{
Habitat Choice by Atlantic Salmon Parr in Relation to Turbulence at a Reach Scale
}

\author{
Eva C. ENDERs* \\ National Oceanic and Atmospheric Administration, National Marine Fisheries Service, \\ Northwest Fisheries Science Center, 2725 Montlake Boulevard East, \\ Seattle, Washington 98112-2097, USA \\ Mathieu L. Roy \\ Département de Géographie, Université de Montréal, \\ CP 6128, Succursale Centre-Ville, Montréal, Québec H3C 3J7, Canada \\ MichaËL OVIDIO \\ Biology of Behavior Unit, Laboratory of Fish Demography and Hydroecology, \\ University of Liège, 10 Chemin de la Justice, 4500 Tihange, Belgium \\ ÉRIC J. HALLOT \\ Hydrology and Fluvial Geomorphology Research Center, \\ University of Liège, 2 Allée du 6 Août, 4000 Liège, Belgium \\ Claudine Boyer \\ Département de Géographie, Université de Montréal, \\ CP 6128, Succursale Centre-Ville, Montréal, Québec H3C 3J7, Canada \\ FrançoIs PetIT \\ Hydrology and Fluvial Geomorphology Research Center, University of Liège, \\ 2 Allée du 6 Août, 4000 Liège, Belgium \\ ANDRÉ G. ROY \\ Département de Géographie, Université de Montréal, \\ CP 6128, Succursale Centre-Ville, Montréal, Québec H3C 3J7, Canada
}

\begin{abstract}
The variables commonly used to describe the physical habitat of Atlantic salmon Salmo salar parr are average velocity, water depth, and substrate. A variety of micro- and mesohabitat models have been developed using these variables to assess habitat quality. However, Atlantic salmon parr live in highly turbulent streams and rivers in which intense fluctuations of water velocity occur. Laboratory experiments have shown that turbulence affects the behavior and energetics of fish. Nevertheless, habitat use in relation to the strong temporal variability of velocity in natural environments has rarely been studied. In this study, Atlantic salmon parr habitat was examined in relation to turbulence in the Patapédia River, Quebec. Rather than taking the usual approach of surveying a large population at one point in time, we used an intensive radiotelemetry tracking survey that focused on the habitat use of a few individual fish over an extended period. We analyzed habitat use in relation to several dynamic hydraulic variables. Our results revealed that under naturally turbulent conditions, the parr displayed high individual variability in their habitat use. Such heterogeneous use of habitat suggests that individuals are not constrained to a single habitat type. Furthermore, no differences were observed in habitat use among the four daily periods (dawn, day, dusk, and night) for individual parr.
\end{abstract}

Distribution of Atlantic salmon Salmo salar parr in rivers and streams is strongly affected by the abiotic

\footnotetext{
* Corresponding author: eva.enders@dfo.mpo.gc.ca

${ }^{1}$ Present address: Fisheries and Oceans, Freshwater Institute, 501 University Crescent, Winnipeg, Manitoba R3T 2N6, Canada.
}

Received December 7, 2008; accepted August 12, 2009 Published online December 7, 2009 habitat (Armstrong et al. 2003). Examinations of habitat suitability generally consider standard abiotic variables such as water depth, substrate, and mean and focal point velocity measured at the position of individual fish (deGraaf and Bain 1986; Morantz et al. 1987; Heggenes 1990). Parr are considered to choose focal positions that maximize access to food resources while minimizing energy expenditures (Hughes and Dill 1990). The focal positions are 
situated close to the substrate (Keenleyside and Yamamoto 1961; Enders et al. 2005) and are likely to be more turbulent than locations distant from substrate (Cotel et al. 2006). Recent laboratory studies revealed that turbulence may affect the abundance (Smith et al. 2006), energetics (Enders et al. 2003; Liao et al. 2003), behavior (Keenleyside and Yamamoto 1961; Enders et al. 2005), and distribution of streamdwelling salmonids (Smith et al. 2005). Juvenile salmonids seem to select focal positions characterized by lower turbulence intensities at equal average velocity (Smith 2003; Smith et al. 2005; Cotel et al. 2006) in order to optimize their net energy gain (Railsback et al. 1999).

In the past, it was believed that Atlantic salmon parr use only restricted habitats, but several radiotelemetry studies have recently demonstrated that juvenile Atlantic salmon parr may use much wider home ranges that can extend over an entire river reach (Økland et al. 2004; Enders et al. 2007). Juvenile salmonids seem to take advantage of low turbulence areas on a microhabitat scale (Smith et al. 2005; Cotel et al. 2006; Smith et al. 2006), but does turbulence also affect the habitat choice of juvenile salmonids on reach scale? It is known that the spatial distribution of streamdwelling salmonids may vary due to diel and seasonal changes in behavior of individual fish (Bremset 2000; Johnston et al. 2004). Habitat use may therefore also vary on a daily cycle and among individuals on a mesohabitat scale.

Recent studies have demonstrated correlations between habitat features and turbulence (Crowder and Diplas 2002; Smith and Brannon 2007). These correlations may, however, change as a function of spatial scale. For instance, downstream from boulders and pebble clusters, which are used by fish as cover, turbulence intensity increases, and areas of strong vertical motion may be present on a microhabitat scale (Buffin-Bélanger and Roy 1998). On a mesohabitat or reach scale, turbulent flow patterns are dominated by large-scale flow structures occupying the entire water column, and these are controlled principally by the morphology of the river channel rather than by individual roughness elements (Lamarre and Roy 2005; Legleiter et al. 2007). Lamarre and Roy (2005) showed that the turbulent flow structures do not display a high spatial variability at the reach scale.

In this study, Atlantic salmon parr, which is the resident, nonmigratory phase in the life cycle of juvenile salmonids, were chosen as the study organism. We analyzed the effects of turbulence on the Atlantic salmon parr, regardless of the influence of the conventional habitat variables of average velocity, water depth, and substrate. Turbulence variables exhibit only weak relationships with the standard habitat variables (Crowder and Diplas 2002; Smith and Brannon 2007; Roy et al. 2009). Since the effects of turbulence on fish are still unclear, our analysis included several hydrodynamic variables (such as SD of the streamwise velocity, turbulent kinetic energy, Froude number, and shear stress) to identify the ones most relevant to the fish studied. Individual Atlantic salmon parr were tagged with radio transmitters, which allowed us to document the frequent repositioning ( $\sim$ every $20 \mathrm{~min}$ ) of each individual during the daily cycle.

The objective of this study was to analyze the habitat use of Atlantic salmon parr in relation to dynamic hydraulic variables. We tested two hypotheses: (1) that on a reach scale for all individuals, parr preferentially select habitats with lower turbulence intensities, and (2) that there are differences in the responses of parr to turbulence variations between different times of the day.

\section{Methods}

Study site.-The study was conducted in the Patapédia River, located in the Restigouche watershed, at the border between Quebec and New Brunswick (47 $53^{\prime} 54^{\prime \prime}, 67^{\circ} 27^{\prime} 54^{\prime \prime} \mathrm{W}$; Figure 1). The Patapédia River is a gravel bed river characterized by riffle-pool sequences. Substrate sizes ranged from gravel to boulder. In the approximately 80 -m-long study reach, which was used by the studied individuals, mean river width was $30 \mathrm{~m}$ and flow depth at habitat sampling locations ranged between 0.25 and $1.65 \mathrm{~m}$ at the time of survey. During the observation periods (August 21 to September 2, 2003, and August 18 to 29, 2004), water temperature ranged from $7.6^{\circ} \mathrm{C}$ to $16.3^{\circ} \mathrm{C}$ and from $10.1^{\circ} \mathrm{C}$ to $13.9^{\circ} \mathrm{C}$, respectively, and water levels, which were relatively stable over the observation period, ranged from 1.38 to $1.43 \mathrm{~m}$ and 1.36 to 1.61 $\mathrm{m}$, respectively.

Fish collection and surgical tagging procedure.Eight Atlantic salmon parr were captured in the river reach by electrofishing (Smith-Root backpack; Model 12-B) in 2003 and 2004 (four each year). Due to the mass of the radio transmitter (ATS, Inc.; Model F1410, $40 \mathrm{MHz}$, trailing whip antenna, $1.0 \mathrm{~g}$ in air), parr larger than $28 \mathrm{~g}$ were chosen to ensure that tag-to-body mass ratio was always less than $3.5 \%$ (Table 1) and the length of the trailing antenna was only $210 \mathrm{~mm}$ (Murchie et al. 2004). Studies analyzing the impact of radio transmitters on fish swimming performance have shown that the surgical implantation of radio transmitters into juvenile salmonids representing up to $12 \%$ of fish body mass did not affect their swimming performance (Adams et al. 1998; Robertson et al. 2003). Fish were immediately anesthetized in a 

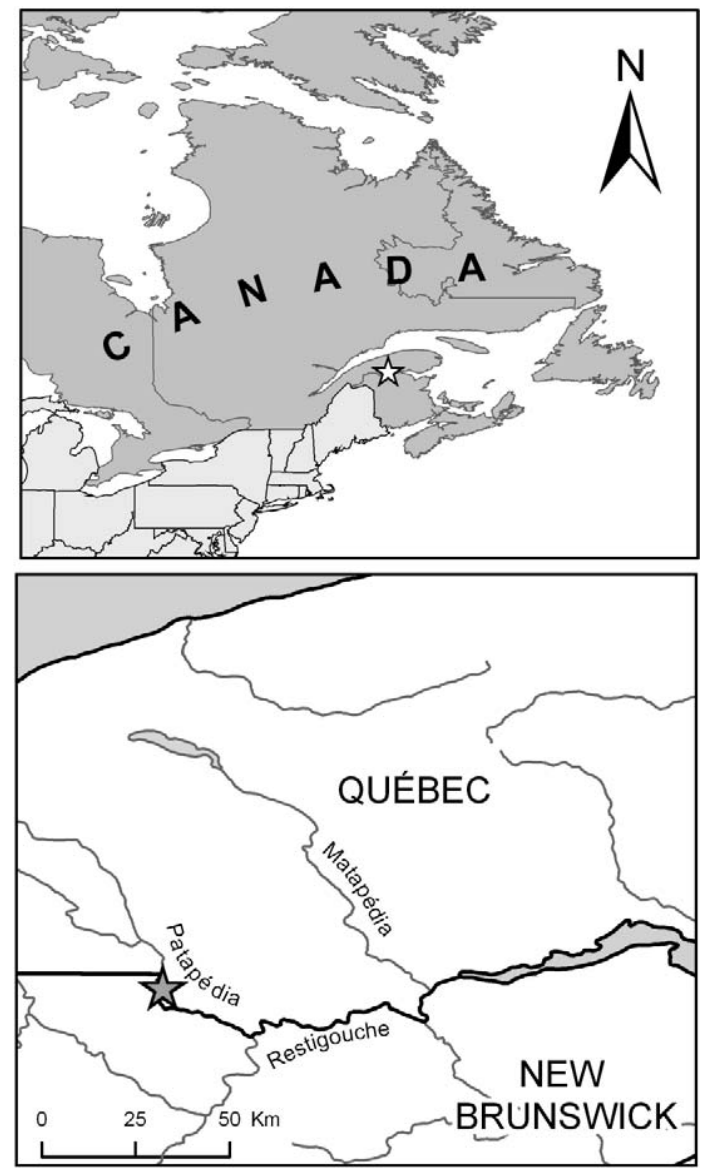

FIgURE 1.-Location of the study site in the Patapédia River (4753’54"N, 67²7’54"W).

solution of 2-phenoxy-ethanol of $0.2 \mathrm{~mL} / \mathrm{L}$. Subsequently, fish were laid with their ventral side uppermost, on a molded tissue soaked with anesthesia. A midventral incision was made and a radio transmitter was inserted. The transmitter antenna was threaded through the body wall approximately $5 \mathrm{~mm}$ posterior and dorsal to the incision (Robertson et al. 2003), and the incision was closed with two independent sutures (Vycril, 5/0 and 3/8 circle). After surgery, fish were allowed a short recovery $(\sim 5 \mathrm{~min})$ in a holding tank before they were released close to their capture site. This short recovery period was chosen to reduce potential effects of postoperative care. For the first $24 \mathrm{~h}$ after surgery, fish were not tracked to exclude potential tagging effects.

Radio-tracking.-From August 23 to 29, 2003, and August 20 to 26, 2004, we tracked the fish every 20 min during two periods (0300-0800 hours and 17002200 hours). The time periods were selected to account
TABLE 1.-Fork lengths and body masses of Atlantic salmon parr selected for the radiotelemetry study. The tag ratio is the ratio of tag weight to fish body mass.

\begin{tabular}{ccccc}
\hline Fish & $\begin{array}{c}\text { Fork } \\
\text { length }(\mathrm{cm})\end{array}$ & $\begin{array}{c}\text { Body } \\
\text { mass }(\mathrm{g})\end{array}$ & $\begin{array}{c}\text { Tag } \\
\text { ratio (\%) }\end{array}$ & Tagging date \\
\hline 1 & 135 & 30.4 & 3.3 & Aug 21, 2003 \\
2 & 137 & 28.2 & 3.5 & Aug 21, 2003 \\
3 & 131 & 28.2 & 3.5 & Aug 21, 2003 \\
4 & 139 & 29.6 & 3.4 & Aug 21, 2003 \\
5 & 143 & 36.2 & 2.8 & Aug 18, 2004 \\
6 & 131 & 28.4 & 3.5 & Aug 18, 2004 \\
7 & 135 & 29.3 & 3.4 & Aug 22, 2004 \\
8 & 128 & 29.5 & 3.4 & Aug 22, 2004 \\
\hline
\end{tabular}

for the daily activity patterns during dawn (0450-0650 hours, six observation per fish per daily survey), day (0650-0800 hours and 1700-1850 hours, nine observations), dusk (1850-2050 hours, six observations), and night (2050-2200 hours and 0300-0450 hours, 10 observations).

Fish were tracked with radio receivers (ATS; FieldMaster) and directional loop antennas (ATS) using a triangulation method. Georeferenced landmarks were positioned $10 \mathrm{~m}$ apart along the river bench of the study reach and equipped with a fixed, north-oriented graduated circle (see Ovidio et al. 2007 for details). Parr were tracked from three different spatially referenced landmarks. Using the variation of power in the radio signal, the observer detected minimum signal strength, which corresponds to fish direction, and then determined the corresponding azimuth. These data were transmitted by radio to calculate and map fish positions via triangulation. Methodological testing with artificially placed transmitters demonstrated that the accuracy of the locations was within $1.4 \mathrm{~m}$ in $90 \%$ of the trials.

Physical habitat assessment.-After $7 \mathrm{~d}$ of fish tracking, we conducted topographical surveys of the riverbed using a tacheometric station (Leica Geosystems AG; TC-805 L). Velocity was measured using two acoustic Doppler velocimeters (ADV; Sontek), which allowed simultaneous measurement of the threedimensional velocity components (streamwise $u$, lateral $v$, and vertical $w$ ) at a frequency of $25 \mathrm{~Hz}$. A total of 584 velocity time series were measured within the 80 $\mathrm{m}$-long reach in which the fish were observed. Velocity time series were recorded over at least $1 \mathrm{~min}$, as recommended by Buffin-Bélanger and Roy (2005) for similar data. Flow was sampled $10 \mathrm{~cm}$ above the riverbed on the nodes of a $2-\mathrm{m} \times 2-\mathrm{m}$ grid within the river reach.

Data and statistical analyses.-The velocity time series were visually inspected to detect any anomaly in the signal. Velocity time series were then processed in 
TABLE 2.- Habitat availability and use by eight radio-tagged Atlantic salmon parr with respect to velocity fluctuation $\left(u_{\mathrm{SD}}\right)$, kinetic energy (TKE), Froude number $\left(\mathrm{Fr}_{0}\right)$, and shear stress $\left(\tau_{0}\right)$; see text for further details. Mann-Whitney $U$-tests were used to compare habitat availability and use.

\begin{tabular}{|c|c|c|c|c|c|c|}
\hline \multirow[b]{2}{*}{ Variable } & \multirow[b]{2}{*}{ Statistic } & \multirow{2}{*}{$\begin{array}{c}\text { Habitat } \\
\text { available, } \\
2003\end{array}$} & \multicolumn{4}{|c|}{ Habitat use by parr: } \\
\hline & & & 1 & 2 & 3 & 4 \\
\hline \multirow{4}{*}{$u_{\mathrm{SD}}(\mathrm{cm} / \mathrm{s})$} & Mean & 11.6 & 4.8 & 8.7 & 13.3 & 15.0 \\
\hline & Range & $0.0-30.9$ & $0.0-23.5$ & $0.1-19.8$ & $0.0-23.4$ & $6.2-30.6$ \\
\hline & $U$ & & -12.5 & -5.3 & -3.3 & -5.4 \\
\hline & $P$ & & $<0.0001$ & $<0.0001$ & 0.001 & $<0.0001$ \\
\hline \multirow[t]{4}{*}{ TKE $\left(\mathrm{cm}^{2} / \mathrm{s}^{2}\right)$} & Mean & 192.6 & 58.8 & 116.8 & 215.6 & 265.0 \\
\hline & Range & $0.0-954.6$ & $0.3-583.9$ & $0.3-416.9$ & $0.1-530.0$ & $40.5-1107.4$ \\
\hline & $U$ & & -12.5 & -5.3 & -3.3 & -5.3 \\
\hline & $P$ & & $<0.0001$ & $<0.0001$ & 0.001 & $<0.0001$ \\
\hline \multirow[t]{4}{*}{$\mathrm{Fr}_{0}$} & Mean & 0.2 & 0.1 & 0.1 & 0.2 & 0.3 \\
\hline & Range & $0.0-0.6$ & $0.0-0.6$ & $0.0-0.2$ & $0.0-0.3$ & $0.2-0.4$ \\
\hline & $U$ & & -12.6 & -8.5 & -1.3 & -11.5 \\
\hline & $P$ & & $<0.0001$ & $<0.0001$ & 0.2 & $<0.0001$ \\
\hline \multirow{4}{*}{$\tau_{0}\left(\mathrm{~g} \cdot \mathrm{cm}^{-1} \cdot \mathrm{s}^{-2}\right)$} & Mean & 30.1 & 7.9 & 15.4 & 38.8 & 42.3 \\
\hline & Range & $0.2-220.9$ & $0.0-122.1$ & $0.0-85.7$ & $0.0-106.5$ & $0.0-218.2$ \\
\hline & $U$ & & -12.1 & -5.9 & -4.8 & -5.6 \\
\hline & $P$ & & $<0.0001$ & $<0.0001$ & $<0.0001$ & $<0.0001$ \\
\hline
\end{tabular}

WinADV (http://www.usbr.gov/wrrl/twahl/winadv) by filtering times series from data points with correlations of less than $70 \%$ and signal-to-noise ratios of less than 20 , as suggested by the manufacturer and Lane et al. (1998).

We used the following four variables to describe the turbulent condition: SD of the streamwise velocity, turbulent kinetic energy, Froude number, and shear stress.

Standard deviation of the streamwise velocity $\left(u_{\mathrm{SD}}\right.$ [in $\mathrm{cm} / \mathrm{s}$ ], hereafter referred to as velocity fluctuation) was estimated as follows:

$$
u_{\mathrm{SD}}=\sqrt{\frac{1}{n-1} \sum_{i=1}^{n}\left(u_{i}-\bar{u}\right)^{2}},
$$

where $u_{1}, u_{2}, \ldots, u_{n}$ are instantaneous streamwise velocities and $\bar{u}$ is mean streamwise velocity of a given velocity time series (in $\mathrm{cm} / \mathrm{s}$ ).

The turbulent kinetic energy (TKE $\left[\right.$ in $\mathrm{cm}^{2} / \mathrm{s}^{2}$ ], hereafter referred to as kinetic energy) is a measure based on the sum of the variances of the velocity fluctuations of all three velocity components, that is,

$$
\mathrm{TKE}=0.5\left(u_{\mathrm{SD}}^{2}+v_{\mathrm{SD}}^{2}+w_{\mathrm{SD}}^{2}\right),
$$

where $u_{\mathrm{SD}}, v_{\mathrm{SD}}$, and $w_{\mathrm{SD}}$ are, respectively, the SDs of the streamwise (longitudinal), lateral, and vertical velocity components (in $\mathrm{cm} / \mathrm{s}$ ).

The Froude number $(\mathrm{Fr})$ is a dimensionless variable comparing the inertial forces with gravitational forces in the flow using the ratio of the mean streamwise velocity (measured at 0.6 times the water depth) to the water depth. In the present study, we calculated a similar index, referred to as bed Froude number $\left(\mathrm{Fr}_{0}\right.$, hereafter referred to as Froude number) using the ratio of the mean streamwise velocity close to the bed to the water depth:

$$
\operatorname{Fr}=\frac{\bar{u}}{\sqrt{g \cdot d}},
$$

where $\bar{u}$ is the mean streamwise velocity measured 10 $\mathrm{cm}$ above the riverbed (in $\mathrm{cm} / \mathrm{s}$ ), $g$ is the acceleration due to gravity (in $\mathrm{cm} / \mathrm{s}^{2}$ ), and $d$ is the water depth $(\mathrm{cm})$. Water depth and velocity are known to be important predictors of fish habitat quality (deGraaf and Bain 1986; Morantz et al. 1987). Due to its dimensionless nature and significance in characterizing flow hydraulics, the Froude number has been proposed as a single descriptor for hydraulic habitat modeling, being more versatile than the use of water depth and velocity independently (Lamouroux and Souchon 2002; Moir et al. 2006). Furthermore, the Froude number is widely used in open-channel hydraulics as a powerful descriptor of the flow state and regime in streams.

Shear stress $\left(\tau\right.$, in $\left.\mathrm{g} \cdot \mathrm{cm}^{-1} \cdot \mathrm{s}^{-2}\right)$ is a common variable used to characterize sediment transport and deposition (Biron et al. 2004). It is possible to estimate bed shear stress $\left(\tau_{0}\right)$ from the Reynolds stress $\equiv \rho \overline{u^{\prime} w^{\prime}}$ as

$$
\tau_{0}=-\rho \overline{u^{\prime} w^{\prime}},
$$

where $\rho$ is water density (in $\mathrm{g} / \mathrm{cm}^{3}$ ), and $\overline{u^{\prime} w^{\prime}}$ (in $\mathrm{cm}^{2}$ / $s^{2}$ ) is the covariance between the streamwise and vertical velocity components. Positions of streamdwelling salmonids are often associated with shear stress that occurs when water flows around pebbles and boulders (Fausch 1984; Smith et al. 2005). With their streamlined body shape, salmonids are evolutionarily 
TABLE 2.-Extended.

\begin{tabular}{|c|c|c|c|c|c|}
\hline \multirow[b]{2}{*}{ Variable } & \multirow{2}{*}{$\begin{array}{c}\text { Habitat } \\
\text { available, } \\
2004\end{array}$} & \multicolumn{4}{|c|}{ Habitat use by parr: } \\
\hline & & 5 & 6 & 7 & 8 \\
\hline \multirow[t]{5}{*}{$u_{\mathrm{SD}}(\mathrm{cm} / \mathrm{s})$} & 15.4 & 16.1 & 13.4 & 13.0 & 15.0 \\
\hline & $4.6-25.4$ & $5.0-31.1$ & $5.0-24.6$ & $5.8-24.3$ & $3.3-24.7$ \\
\hline & & -0.8 & -3.1 & -2.2 & -0.6 \\
\hline & & 0.4 & 0.002 & 0.02 & 0.5 \\
\hline & 265.3 & 298.3 & 242.6 & 209.4 & 291.8 \\
\hline \multirow[t]{4}{*}{$\operatorname{TKE}\left(\mathrm{cm}^{2} / \mathrm{s}^{2}\right)$} & $22.6-765.9$ & $28.8-897.8$ & $33.6-756.0$ & $34.8-527.5$ & $12.0-675.1$ \\
\hline & & -1.2 & -1.0 & -1.8 & -1.5 \\
\hline & & 0.2 & 0.3 & 0.7 & 0.1 \\
\hline & 0.2 & 0.1 & 0.1 & 0.1 & 0.1 \\
\hline \multirow[t]{4}{*}{$\mathrm{Fr}_{0}$} & $0.1-0.4$ & $0.0-0.3$ & $0.0-0.3$ & $0.0-0.3$ & $0.0-0.3$ \\
\hline & & -3.4 & -4.9 & -4.0 & -6.1 \\
\hline & & 0.001 & $<0.0001$ & $<0.0001$ & $<0.0001$ \\
\hline & 32.7 & 41.1 & 14.9 & 21.9 & 15.0 \\
\hline \multirow[t]{3}{*}{$\tau_{0}\left(\mathrm{~g} \cdot \mathrm{cm}^{-1} \cdot \mathrm{s}^{-2}\right)$} & $0.0-170.7$ & $0.0-209.9$ & $0.0-163.4$ & $0.4-85.9$ & $0.0-92.3$ \\
\hline & & -1.6 & -5.1 & -2.2 & -4.6 \\
\hline & & 0.1 & $<0.0001$ & 0.03 & $<0.0001$ \\
\hline
\end{tabular}

well adapted to severe velocities and velocity fluctuation, and may use shear stress and turbulence to their advantage while swimming head-on into the flow (Liao et al. 2003). However, if flow is coming from behind or at extremely high levels (e.g., in hydroelectric turbines), shear stresses can lead to sublethal physiological effects on fish equilibrium (Ferguson et al. 2006), lift and tear off scales, pry open the operculum, rupture or dislodge eyes, and damage gills (Odeh et al. 2002; Neitzel et al. 2004; Deng et al. 2005).

Maps of these four turbulence variables were created using linear interpolation in Vertical Mapper 3.0 in MapInfo Professional 7.0. Positions of parr were overlaid on these maps to examine the habitat use of individual fish in relation to habitat availability. Values of each hydraulic variable at the fish positions were extracted to compare the frequency distribution of habitat use and availability. We tested for differences between use and availability for each hydraulic variable using Mann-Whitney tests.

Finally, velocity fluctuation, kinetic energy, Froude number, and shear stress used by individual parr were categorized in four daily periods. We then compared the habitat use of each parr among dusk, day, dawn, and night periods using a Friedman test. Significance was set at an $\alpha$-level of 0.05 for all statistical tests, and Bonferroni adjustments were used for multiple comparisons $(\alpha / n=0.05 / 32 ; P=0.002)$. All statistical analyses were performed using SPSS 11.0.

\section{Results \\ Dynamic Hydraulic Habitat}

We observed a wide range of turbulent conditions available to Atlantic salmon parr (Table 2). Velocity fluctuation $\left(u_{\mathrm{SD}}\right)$ ranged in 2003 from 0.0 to $30.9 \mathrm{~cm} / \mathrm{s}$ and in 2004 from 4.6 to $25.4 \mathrm{~cm} / \mathrm{s}$. Observed values of kinetic energy (TKE) varied between 0.0 and 954.6 $\mathrm{cm}^{2} / \mathrm{s}^{2}$ in 2003 and between 22.6 and $765.9 \mathrm{~cm}^{2} / \mathrm{s}^{2}$ in 2004. Froude number $\left(\mathrm{Fr}_{0}\right)$ ranged from 0.0 to 0.6 in 2003 and from 0.1 to 0.4 in 2004 , respectively. Finally, a 1,105-fold and 17,000-fold difference in shear stress $\left(\tau_{0}\right)$ was observed within the river reach in 2003 and 2004, respectively.

\section{Habitat Use of Atlantic Salmon Parr in Relation to Habitat Availability}

In 2003, significant differences were observed between available and used habitat for all fish and all hydraulic habitat variables (Mann-Whitney $U$-tests: all $P \leq 0.001$, except for $\mathrm{Fr}_{0}$ of parr 3). However, habitat selection was inconsistent between individual fish. For example, parr 1 and parr 2 were observed in habitats with significantly lower values for all four hydraulic variables than available. In contrast, parr 3 and 4 selected habitats with higher values for the hydraulic variables, which corresponded to more turbulent conditions (Figure 2a-d).

During 2004, significant differences between available and used habitat were observed for only one parr with regard to velocity fluctuation. Parr 7 was observed in habitats characterized by lower velocity fluctuation than the average value available (Mann-Whitney test: $P=0.002$; Figure 2a). No significant differences between available and used habitat were observed for kinetic energy (Mann-Whitney tests: all $P>0.002$; Figure 2b). However, all four fish (5-8) selected habitats with a lower Froude number (Mann-Whitney tests: $P \leq 0.001$; Figure 2c) and two (6 and 8) selected 

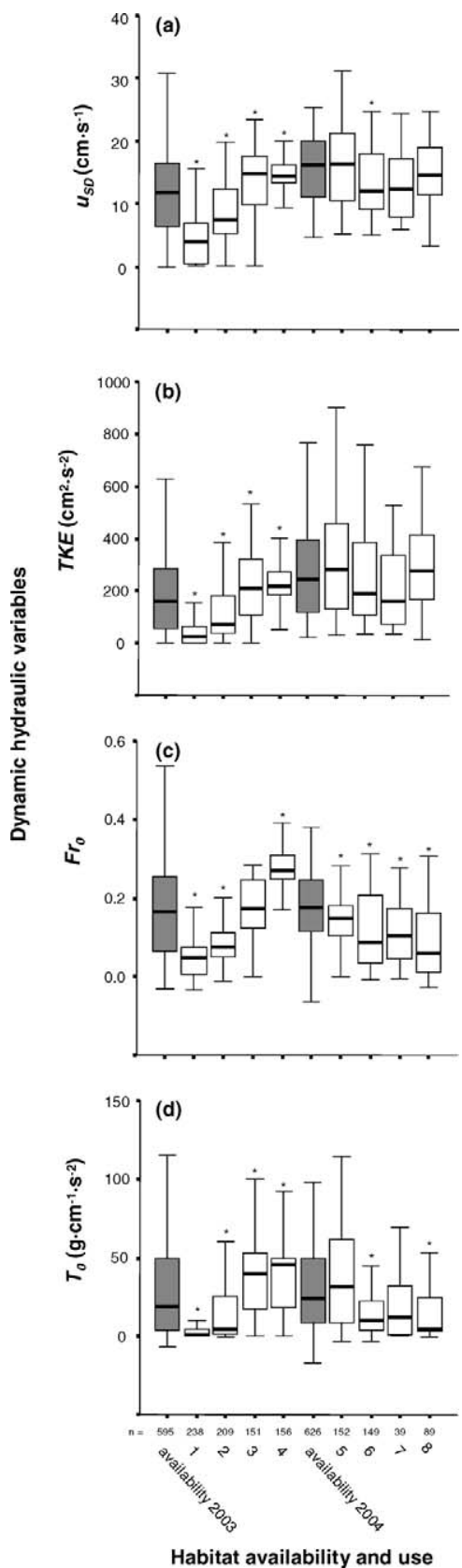

FIGURE 2.-Box-and-whisker plots of habitat availability in 2003 and 2004 (shaded symbols) and habitat utilization (open symbols) by eight Atlantic salmon parr (1-8) with respect to (a) velocity fluctuation $\left(u_{\mathrm{SD}}\right)$, (b) kinetic energy (TKE), (c) Froude number $\left(\mathrm{Fr}_{0}\right)$, and $(\mathbf{d})$ shear stress $\left(\tau_{0}\right)$. Significant differences between habitat availability and use are indicated asterisks. The horizontal lines forming the bottom, middle, and top of each box represent the 25th, 50th, and 75th percentiles of the observations, respectively; the vertical lines at the bottom and top of each box represent the 5th and 95th percentiles, respectively. habitats with lower shear stress than the average available (Mann-Whitney tests: $P \leq 0.001$; Figure $2 \mathrm{~d}$ ). In general, the comparison of habitat availability in the river reach versus habitat use by parr revealed that individual parr used a broad range of turbulence conditions in a relatively short period rather than staying in a restricted range of turbulence (Table 2).

\section{Temporal Variations in Habitat Use of Parr}

Interestingly, no significant differences were observed in habitat use of velocity fluctuation, kinetic energy, Froude number, and shear stress among the four daily periods of dawn, day, dusk, and night for any of the eight Atlantic salmon parr surveyed (Friedman test: all $P>0.002$; Figure 3).

\section{Discussion}

We analyzed habitat use of individual streamdwelling parr in relation to hydraulic variables that capture aspects of turbulence. This approach is based on recent studies that have shown that behavior and swimming costs of fish are affected by the intensity of turbulence (Pavlov et al. 2000; Enders et al. 2003; Liao et al. 2003; Smith et al. 2005; Cotel et al. 2006). In our study, all four dynamic hydraulic variables used to describe turbulence revealed relevant habitat choices by parr. Although most fish were observed over the entire range of habitat available, most parr seem to preferentially use areas with lower Froude number. There was also a tendency that more fish were observed at lower shear stress. Parr may choose areas of reduced turbulence to decrease their energy cost as the energetic cost of swimming may increase with increasing turbulence intensity (Enders et al. 2003). The observed variability among individuals might result from genetically determined differences in the bioenergetics of the anadromous and precocious Atlantic salmon parr similar to the bioenergetics differences observed between anadromous and resident brook trout Salvelinus fontinalis that are seeking different energetic environments (Morinville and Rasmussen 2003).

We did not find temporal differences in the habitat use in relation to turbulence flow variables, even though this might be suspected because fish may select different habitats over the daily cycle, driven by various biological activities such as feeding and resting. During summer Atlantic salmon parr are predominately active during the day, but some activity also occurs during hours of darkness (Higgins and Talbot 1985; Fraser et al. 1995; Gries et al. 1997). However, Orpwood et al. (2006) showed, in contrast, that parr may be diurnal only to the extent needed to 
sustain their growth rate, which depends on food availability, supporting our results. During autumn and winter when water temperature drops below $8-12^{\circ} \mathrm{C}$, parr shelter in the interstitial space of the substrate during the day (Rimmer et al. 1983; Cunjak 1988) and emerge at darkness to feed (Fraser et al. 1993; Valdimarsson et al. 1997). Consequently, Atlantic salmon parr are known to display complex diel activity patterns and cannot be considered as entirely diurnal, crepuscular, or nocturnal. Although the daily activity pattern of Atlantic salmon parr was not reflected in habitat use in terms of the four dynamic hydraulic variables evaluated, it is possible that Atlantic salmon parr track velocity fluctuations over longer time scales, such as seasonal changes in discharge that affect the local velocities (Nislow et al. 1999).

Habitat models for juvenile stream-dwelling salmonids have been developed on both a micro- and a mesohabitat scale (Guay et al. 2000; Guensch et al. 2001; Borsányi et al. 2004). In gravel bed rivers, the presence of roughness elements (such as protuberant boulders) affects turbulence only at a local scale and over short distances (Buffin-Bélanger and Roy 1998). Recently, it has been shown that on a microhabitat scale, juvenile salmonids select focal position characterized by lower turbulence intensities at equal average velocity (Smith 2003; Smith et al. 2005; Cotel et al. 2006). Turbulent velocity patterns on the reach scale are dominated by large-scale flow structures occupying the entire water column, and these are controlled principally by the morphology of the river channel rather than by individual roughness elements (Lamarre and Roy 2005; Legleiter et al. 2007).

It is likely that juveniles react to flow heterogeneity on smaller distances of centimeters to body length. This scale was, however, unidentifiable at the resolution available for both fish positioning and the velocity measurements in this study. Therefore, we can only speculate that Atlantic salmon parr may be using microhabitat refuges (e.g., behind protuberant boulders) characterized by reduced turbulence. Furthermore, the variability observed in habitat use among individuals with respect to turbulence may be due to other habitat variables, which may override habitat selection based on turbulence (Heggenes 2002). Alternatively, there may be a strong preference for specific turbulence characteristics, but an individual may be forced by competition to use alternative habitat characterized by flow conditions other than those preferred (McLaughlin and Grant 1994; MacLean et al. 2005; Kemp et al. 2006). Whereas Atlantic salmon parr seem to react and respond to turbulence on a smaller microhabitat scale, the application of dynamic hydrau- lic variables on reach scale seem to not provide a useful tool for fisheries and habitat managers.

There are intrinsic trade-offs in any study design. In this study, we made three principal trade-offs. Firstly, additional data were derived from an intensive radiotracking survey, which was offset by the use of only a few fish. With a larger sample size, the cost would have been less-frequent observations. However, the intensive radio-tracking methodology was used by Ovidio et al. (2007) to investigate space utilization and mobility patterns of individual Atlantic salmon parr over short time scales with frequent detections of position, revealing that parr may be far more mobile and have larger home ranges than previously assumed. Close tracking also indicated high variability among individuals in terms of both range size and habitat use. Subsampling of the mobility data obtained from Atlantic salmon parr (two and six observations out of 32/d) demonstrated a significant loss in precision and accuracy of estimates on mobility patterns and home ranges (Ovidio et al. 2007). Frequent observations were therefore necessary to fully describe parr utilization of space. Consequently, the intense survey of a small number of fish successfully contributes to the overall picture of Atlantic salmon parr habitat use. However, given the high variation seen among individual parr with regard to habitat use, a larger sample size will be needed to generalize about observed traits for the population, particular as only larger parr were studied due to the size of the radiotelemetry transmitter.

The second trade-off was in regard to hydraulics by making detailed measurements and calculations of turbulence variables on a broad grid rather than less detailed measurements at a microhabitat scale. Considering that the turbulent flow structures do not display a high spatial variability at the reach scale (Lamarre and Roy 2005) and that there is a high similarity between flow structure properties characterized near the bed and in the outer region of the flow (Roy et al. 1996), we found it appropriate to measure the flow velocity at one point close to riverbed where Atlantic salmon parr are found on a wide grid.

Thirdly, in this study, the choice of a point velocity measurement approach at a single height was based on a trade-off between sampling efficiency and ecological relevance. Sampling at a single point allowed us to cover the extent of the study reach while remaining at a constant flow stage. Measuring $10 \mathrm{~cm}$ above the bed rather than at nose velocity prevented excessive bottom echo noise arising from the pulse signals rebounding off the heterogeneous gravel bed. This problem can be severe when measurements are taken too close to the bed, thus leading to low-quality data. Furthermore, juvenile Atlantic salmon spend most of their time 

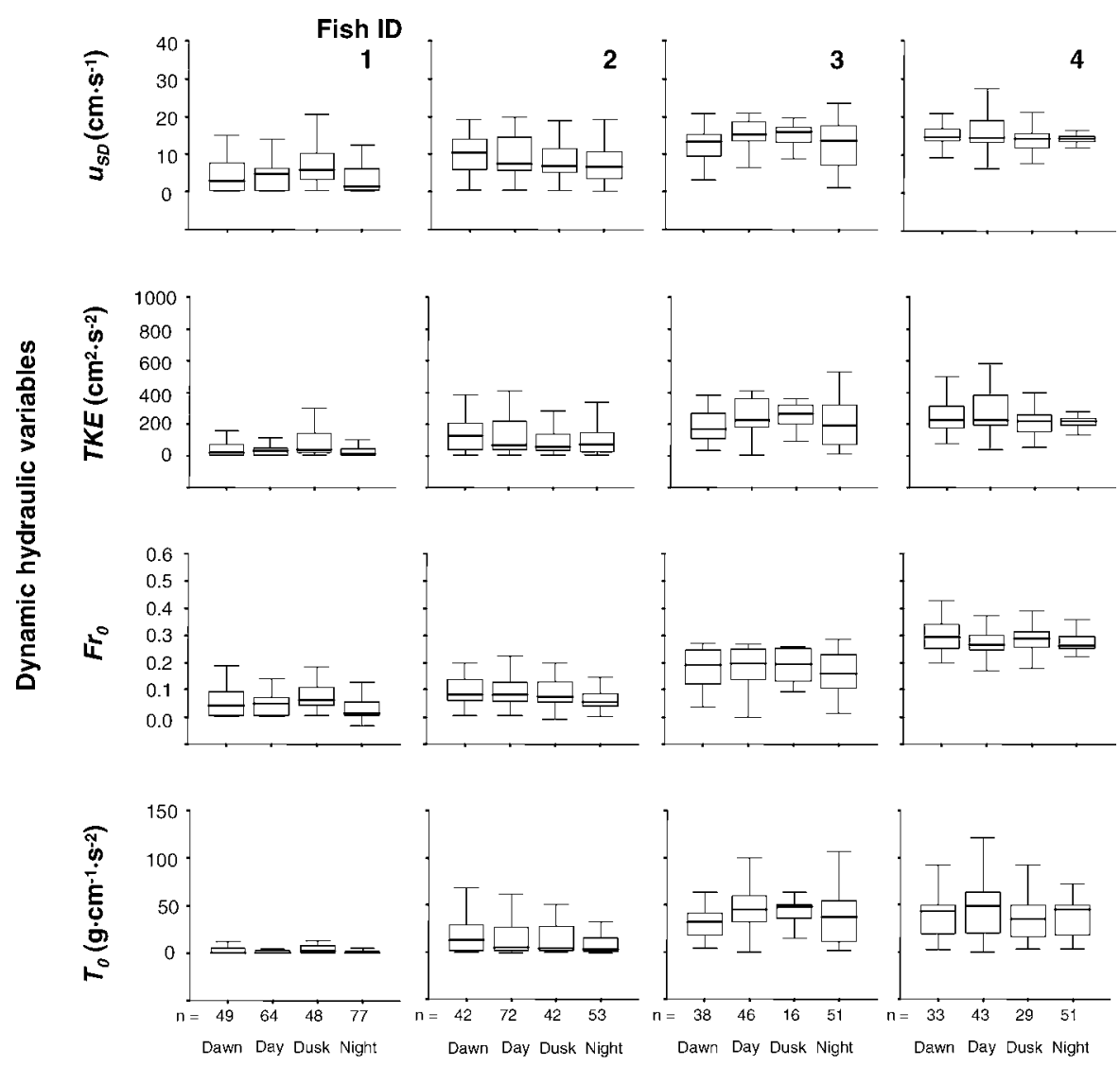

\section{Daily periods}

FIGURE 3.-Box-and-whisker plots of habitat use by eight Atlantic salmon parr (1-8) with respect to velocity fluctuation $\left(u_{\mathrm{SD}}\right)$, kinetic energy (TKE), Froude number $\left(\mathrm{Fr}_{0}\right)$, and shear stress $\left(\tau_{0}\right)$ during four diel time periods (dusk, day, dawn, and night). See Figure 2 for additional details.

sitting and waiting on the riverbed, where velocity is very low. Hence, a major part of their energy expenditure are related to burst movements in the water column to catch drifting prey (Hughes and Dill 1990). Given the range of flow depths in the reach at velocity measurement locations $(25-165 \mathrm{~cm}), 10 \mathrm{~cm}$ above the bed represents a relative height ranging from 0.06 and $0.40 \mathrm{~cm}$. For most of the reach $(80 \%)$, the relative height of the velocity measurements was within $0.2 \mathrm{~cm}$ of the flow depth. The decision to sample at $10 \mathrm{~cm}$ above the bed was also justified by the fact that averages of turbulence variables (such as SDs of the velocity fluctuations and Reynolds shear stress) are quite stable in the near-bed region. Profiles of mean and turbulent flow properties in gravel bed rivers show consistent patterns in spite of the roughness and heterogeneity of gravel beds (Buffin-Bélanger and Roy 1998; Roy et al. 2004). The consistent vertical patterns and the relative stability of the average turbulent variables on a vertical profile are due to the presence of macroturbulent flow structures that occupy the entire depth of the flow and that dominate turbulence production (Buffin-Bélanger et al. 2000; Roy et al. 2004). These structures are narrow wedges of low- and high-speed fluid that scale with flow depth. Their length ranges between two to six times the water depth. Locally the wedges interact with the larger boulders and pebble clusters that protrude from the bed. This interaction tends to maintain the wedge structure through feedback effects and the disturbance caused by protruding clasts are local (Lamarre and Roy 2005; Lacey and Roy 2007). Furthermore, in a wide range of bed size material context, velocities measured at $10 \mathrm{~cm}$ above the bed have been proven effective in estimating thresholds of particle entrainment in gravel bed rivers and favored over velocities measured 1.5, 

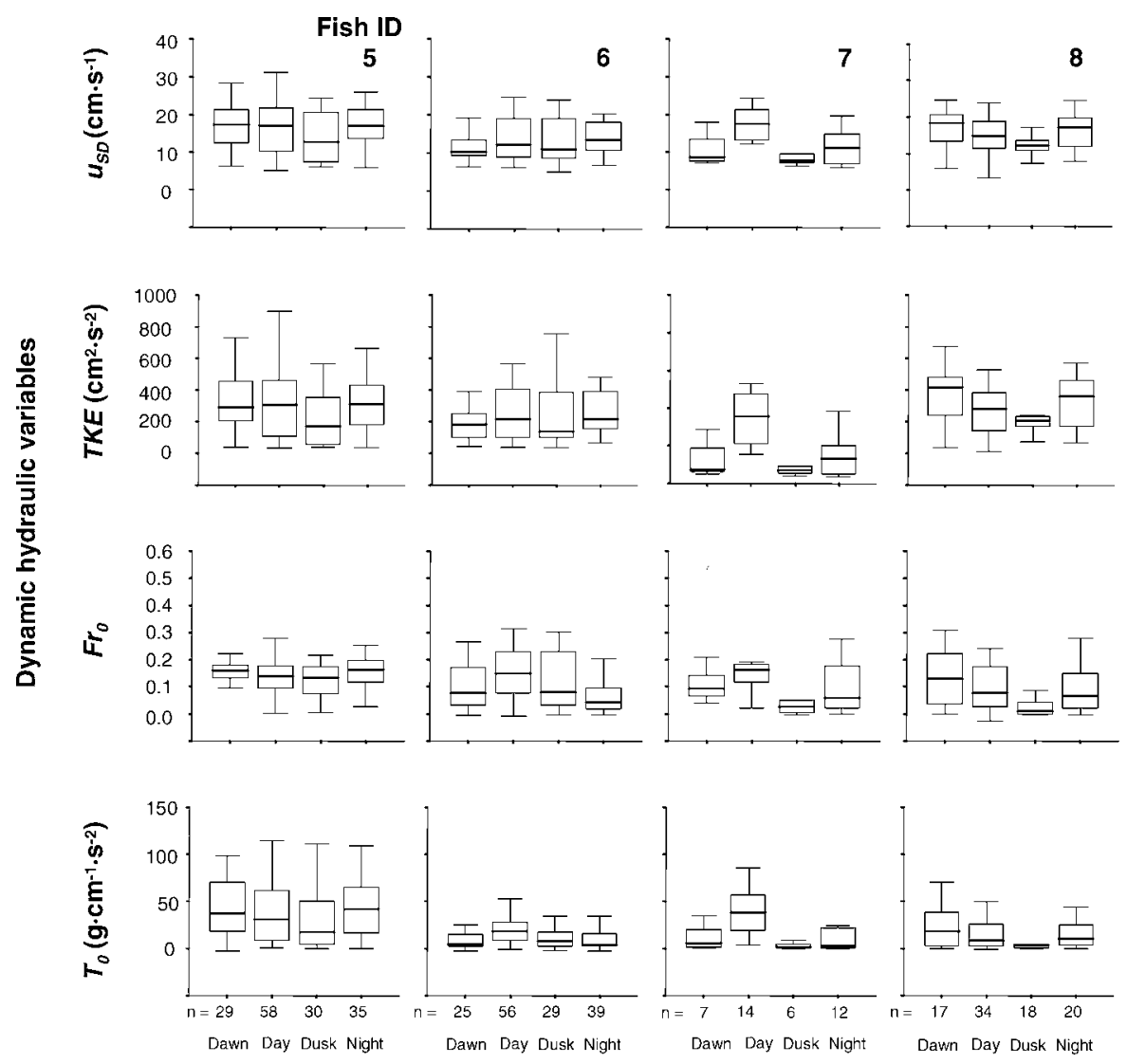

\section{Daily periods}

FIGURE 3.-Continued.

2.5 , or $5.0 \mathrm{~cm}$ above the bed. Thus is it postulated that sampling at $10 \mathrm{~cm}$ above the riverbed captures the signature of near-bed turbulence as well as represents the large-scale turbulent flow structures while allowing for the complete survey of the reach during a relatively short time.

Future research should aim to analyze parr reaction and distribution in relation to variables that account for the spatial aspects of turbulence (such as vorticity and eddy length) on a microhabitat scale. These variables have been shown to affect fish under laboratory settings (Liao et al. 2003). However, determining the effect of a particular variable on fish habitat use is challenging as fish habitat choices may be associated with multiple, correlated variables. For example, food availability is correlated with water velocity (Chapman and Bjornn 1969; Everest and Chapman 1972), which is, in turn, often correlated with turbulent kinetic energy (Cotel et al. 2006). Consequently, it is difficult to separate the effects of individual variables on fish behavior.

Velocity represents a trade-off between food availability and energy costs related to holding in a desired position (Nislow et al. 1999). Thus, if parr select habitat to optimize the balance between energy gains and costs, they would choose areas of moderate velocity and relatively low turbulence that are close to faster velocities (Fausch 1984), which may explain the broad range of habitat use for individual Atlantic salmon parr documented in the present study. Furthermore, turbulence may affect the feeding behavior of parr. Parr seem to adjust to temporal variations in habitat conditions (such as food availability) on a reach scale (Gowan and Fausch 2002). The proportion of time used for feeding decreases with the mean and SD of velocity (Enders et al. 2005). However, on a local scale, parr may demonstrate only minor adjustments to habitat conditions as individual variation in habitat use 
is primarily affected by dominance status (MacLean et al. 2005; Kemp et al. 2006).

\section{Acknowledgments}

This research was funded by the Ministère des Relations Internationales du Québec, the Programme de Coopération Wallonie-Bruxelles/Québec (Communauté française de Belgique), the Ministry of Walloon Region (DGRNE-Meuse Salmon Project), and the Natural Sciences and Engineering Research Council of Canada. The authors thank Damien Sonny, Julie Thérien, and Julien Mols for field assistance, and the Corporation de gestion des Rivières Matapédia et Patapédia and Gaétan Lavoie for logistic support.

\section{References}

Adams, N. S., D. W. Rondorf, S. D. Evans, J. E. Kelly, and R. W. Perry. 1998. Effects of surgically and gastrically implanted radio transmitters on growth and feeding behavior of juvenile Chinook salmon. Transactions of the American Fisheries Society 127:128-136.

Armstrong, J. D., P. S. Kemp, G. J. A. Kennedy, M. Ladle, and N. J. Milner. 2003. Habitat requirements of Atlantic salmon and brown trout in rivers and streams. Fisheries Research 62:143-170.

Biron, P. M., C. Robson, M. F. Lapointe, and S. J. Gaskin. 2004. Comparing different methods of bed shear stress estimates in simple and complex flow fields. Earth Surface Processes and Landforms 29:1403-1415.

Borsányi, P., K. Alfredsen, A. Harby, O. Ugedal, and C. E. Kraxner. 2004. A mesoscale habitat classification method for population modeling of Atlantic salmon (Salmo salar L.) in Norway. Hydroécologie appliquée 14:119-138.

Bremset, G. 2000. Seasonal and diel changes in behaviour, microhabitat use, and preferences by young pooldwelling Atlantic salmon, Salmo salar, and brown trout, Salmo trutta. Environmental Biology of Fishes 59:163179.

Buffin-Bélanger, T., and A. G. Roy. 1998. Effects of a pebble cluster on the turbulent structure of a depth-limited flow in a gravel bed river. Geomorphology 25:249-267.

Buffin-Bélanger, T., and A. G. Roy. 2005. $1 \mathrm{~min}$ in the life of a river: selecting the optimal record length for the measurement of turbulence in fluvial boundary layers. Geomorphology 68:77-84.

Buffin-Bélanger, T., A. G. Roy, and A. D. Kirkbride. 2000. On large-scale flow structures in a gravel bed river. Geomorphology 32:417-435.

Chapman, D. W., and T. C. Bjornn. 1969. Distribution of salmonids in streams, with special reference to food and feeding. Pages 153-176 in T. G. Northcote, editor. Symposium on salmon and trout in streams. University of British Columbia Press, Vancouver.

Cotel, A. J., P. W. Webb, and H. Tritico. 2006. Do brown trout choose locations with reduced turbulence? Transactions of the American Fisheries Society 135:610-619.

Crowder, D. W., and P. Diplas. 2002. Vorticity and circulation: spatial metrics for evaluating flow complex- ity in stream habitats. Canadian Journal of Fisheries and Aquatic Sciences 59:633-645.

Cunjak, R. A. 1988. Behaviour and microhabitat of young Atlantic salmon (Salmo salar) during winter. Canadian Journal of Fisheries and Aquatic Sciences 45:2156-2160.

deGraaf, D. A., and L. H. Bain. 1986. Habitat use by and preferences of juvenile Atlantic salmon in two Newfoundland rivers. Transactions of the American Fisheries Society 115:671-681.

Deng, Z., G. R. Guensch, C. A. McKinstry, R. P. Mueller, D. D. Dauble, and M. C. Richmond. 2005. Evaluation of fish injury mechanisms during exposure to turbulent shear flow. Canadian Journal of Fisheries and Aquatic Sciences 62:1513-1522.

Enders, E. C., D. Boisclair, and A. G. Roy. 2003. The effect of turbulence on the cost of swimming for juvenile Atlantic salmon (Salmo salar). Canadian Journal of Fisheries and Aquatic Sciences 60:1149-1160.

Enders, E. C., T. Buffin-Bélanger, D. Boisclair, and A. G. Roy. 2005. The feeding behaviour of juvenile Atlantic salmon in relation to turbulent flow. Journal of Fish Biology 66:242-253.

Enders, E. C., K. D. Clarke, C. J. Pennell, L. M. N. Ollerhead, and D. A. Scruton. 2007. Comparison between PIT and radiotelemetry to evaluate winter habitat use and activity patterns of juvenile Atlantic salmon and brown trout. Hydrobiologia 582:231-242.

Everest, F. H., and D. W. Chapman. 1972. Habitat selection and spatial interaction by juvenile Chinook salmon and steelhead trout in two Idaho streams. Journal of the Fisheries Research Board of Canada 29:91-100.

Fausch, K. D. 1984. Profitable stream positions for salmonids: relating specific growth rate to net energy gain. Canadian Journal of Zoology 62:441-451.

Ferguson, J. W., R. F. Absolon, T. J. Carlson, and B. P. Sandford. 2006. Evidence of delayed mortality on juvenile Pacific salmon passing through turbines at Columbia River dams. Transactions of the American Fisheries Society 135:139-150.

Fraser, N. H. C., J. Heggenes, N. B. Metcalfe, and J. E. Thorpe. 1995. Low summer temperatures cause juvenile Atlantic salmon to become nocturnal. Canadian Journal of Zoology 73:446-451.

Fraser, N. H. C., N. B. Metcalfe, and J. E. Thorpe. 1993. Temperature-dependent switch between diurnal and nocturnal foraging in salmon. Proceedings of the Royal Society of London B 242:135-139.

Gowan, C., and K. D. Fausch. 2002. Why do foraging stream salmonids move during summer? Environmental Biology of Fishes 64:139-153.

Gries, G., K. G. Whalen, F. Juanes, and D. L. Parrish. 1997. Nocturnal activity of juvenile Atlantic salmon (Salmo salar) in late summer: evidence of diel activity partitioning. Canadian Journal of Fisheries and Aquatic Sciences 54:1408-1413.

Guay, J. C., D. Boisclair, D. Rioux, M. Leclerc, M. Lapointe, and P. Legendre. 2000. Development and validation of numerical habitat models for juveniles of Atlantic salmon (Salmo salar). Canadian Journal of Fisheries and Aquatic Sciences 57:2065-2075.

Guensch, G. R., T. B. Hardy, and R. C. Addley. 2001. 
Examining feeding strategies and position choice of driftfeeding salmonids using an individual-based, mechanistic foraging model. Canadian Journal of Fisheries and Aquatic Sciences 58:446-457.

Heggenes, J. 1990. Habitat utilization and preferences in juvenile Atlantic salmon (Salmo salar) in streams. Regulated Rivers: Research and Management 5:341-354.

Heggenes, J. 2002. Flexible summer habitat selection by wild, allopatric brown trout in lotic environments. Transactions of the American Fisheries Society 131:287-298.

Higgins, P. J., and C. Talbot. 1985. Growth and feeding in juvenile Atlantic salmon (Salmo salar L.). Pages 243263 in C. B. Coey, A. M. Mackie, and J. G. Bell, editors. Nutrition and feeding in fish. Academic Press, London.

Hughes, N. F., and L. M. Dill. 1990. Position choice by driftfeeding salmonids: model and test for Arctic grayling (Thymallus arcticus) in subarctic mountain streams, interior Alaska. Canadian Journal of Fisheries and Aquatic Sciences 47:2039-2048.

Johnston, P., N. E. Bergeron, and J. J. Dodson. 2004. Diel activity patterns of juvenile Atlantic salmon in rivers with summer water temperature near the temperature-dependent suppression of diurnal activity. Journal of Fish Biology 65:1305-1318.

Keenleyside, M. H. A., and F. T. Yamamoto. 1961. Territorial behaviour of juvenile Atlantic salmon (Salmo salar L.). Behaviour 19:139-169.

Kemp, P. S., D. J. Gilvear, and J. D. Armstrong. 2006. Variation in performance reveals discharge-related energy costs for foraging Atlantic salmon (Salmo salar) parr. Ecology of Freshwater Fish 15:565-571.

Lacey, R. W. J., and A. G. Roy. 2007. A comparative study of the turbulent flow field with and without a pebble cluster in a gravel bed river. Water Resources Research 43:W05502.

Lamarre, H., and A. G. Roy. 2005. Reach-scale variability of turbulent flow characteristics in a gravel bed river. Geomorphology 68:95-113.

Lamouroux, N., and Y. Souchon. 2002. Simple predictions of instream habitat model outputs for fish habitat guilds in large streams. Freshwater Biology 47:1531-1542.

Lane, S. N., P. M. Biron, K. F. Bradbrook, J. B. Butler, J. H. Chandler, M. D. Crowell, S. J. McLelland, K. S. Richards, and A. G. Roy. 1998. Three-dimensional measurements of river channel flow processes using acoustic Doppler velocimetry. Earth Surface Processes and Landforms 23:1247-1267.

Legleiter, C. J., T. L. Phelps, and E. E. Wohl. 2007. Geostatistical analysis of the effects of stage and roughness on reach-scale spatial patterns of velocity and turbulence intensity. Geomorphology 83:322-345.

Liao, J. C., D. N. Beal, G. V. Lauder, and M. S. Triantafyllou. 2003. Fish exploiting vortices decrease muscle activity. Science 302:1566-1569.

MacLean, A., F. A. Huntingford, G. D. Ruxton, I. J. Morgan, J. Hamilton, and J. D. Armstrong. 2005. Testing the assumptions of the ideal despotic distribution with an unpredictable food supply: experiments in juvenile salmon. Journal of Animal Ecology 74:214-225.

McLaughlin, R. L., and J. W. A. Grant. 1994. Morphological and behavioural differences among recently emerged brook charr, Salvelinus fontinalis, foraging in slow- vs. fast-running water. Environmental Biology of Fishes 39:289-300.

Moir, H. J., C. N. Gibbins, C. Soulsby, and J. H. Webb. 2006. Discharge and hydraulic interactions in contrasting channel morphologies and their influence on site utilization by spawning Atlantic salmon (Salmo salar). Canadian Journal of Fisheries and Aquatic Sciences 63:2567-2585.

Morantz, D. L., R. K. Sweeney, C. S. Shirvell, and D. A. Longard. 1987. Selection of microhabitat in summer by juvenile Atlantic salmon (Salmo salar). Canadian Journal of Fisheries and Aquatic Sciences 44:120-129.

Morinville, G. R., and J. B. Rasmussen. 2003. Early juvenile bioenergetic differences between anadromous and brook trout (Salvelinus fontinalis). Canadian Journal of Fisheries and Aquatic Sciences 60:401-410.

Murchie, K. J., S. J. Cooke, and J. F. Schreer. 2004. Effects of radio transmitter antenna length on swimming performance of juvenile rainbow trout. Ecology of Freshwater Fish 13:312-316.

Neitzel, D. A., D. D. Dauble, G. F. Čada, M. C. Richmond, G. R. Guensch, R. P. Mueller, C. S. Abernethy, and B. Amidan. 2004. Survival estimates for juvenile fish subjected to a laboratory-generated shear environment. Transactions of the American Fisheries Society 133:447-454.

Nislow, K. H., C. L. Folt, and D. L. Parrish. 1999. Favorable foraging locations for young Atlantic salmon: application to habitat and population restoration. Ecological Applications 9:1085-1099.

Odeh, M., J. F. Noreika, A. Haro, A. Maynard, T. CastroSantos, and G. F. Čada. 2002. Evaluation of the effects of turbulence on the behavior of migratory fish. Report to the Bonneville Power Administration, Contract 00000022, Project 200005700, Portland, Oregon.

Økland, F., E. B. Thorstad, and T. F. Næsje. 2004. Is Atlantic salmon production limited by number of territories? Journal of Fish Biology 65:1047-1055.

Orpwood, J. E., S. W. Griffiths, and J. D. Armstrong. 2006. Effects of food availability on temporal activity patterns and growth of Atlantic salmon. Journal of Animal Ecology 75:677-685.

Ovidio, M., E. C. Enders, E. J. Hallot, M. L. Roy, J. C. Philippart, F. Petit, and A. G. Roy. 2007. Mobility and home-range use of Atlantic salmon parr over short time scales. Aquatic Living Resources 20:95-101.

Pavlov, D. S., A. I. Lupandin, and M. A. Skorobogatov. 2000. The effects of flow turbulence on the behavior and distribution of fish. Journal of Ichthyology 40(Supplement 2):S232-S261.

Railsback, S. F., R. H. Lamberson, B. C. Harvey, and W. E. Duffy. 1999. Movement rules for individual-based models of stream fish. Ecological Modelling 123:73-89.

Rimmer, D. M., U. Paim, and R. L. Saunders. 1983. Autumnal habitat shift of juvenile Atlantic salmon (Salmo salar) in a small river. Canadian Journal of Fisheries and Aquatic Sciences 40:671-680.

Robertson, M. J., D. A. Scruton, and J. A. Brown. 2003. Effects of surgically implanted transmitters on swimming performance, food consumption, and growth of wild 
Atlantic salmon parr. Journal of Fish Biology 62:673678.

Roy, A. G., T. Buffin-Bélanger, H. Lamarre, and A. D. Kirkbride. 2004. Size, shape, and dynamics of large-scale turbulent flow structures in a gravel bed river. Journal of Fluid Mechanics 500:1-27.

Roy, M. L., A. G. Roy, and P. Legendre. 2009. The relations between "standard" fluvial habitat variables and turbulent flow at multiple scales in morphological units of a gravel bed river. River Research and Applications. DOI: 10.1002/rra.1281.

Roy, A. G., T. Buffin-Bélanger, and S. Deland. 1996. Scales of turbulent coherent flow structures in a gravel bed river. Pages 147-164 in P. J. Ashworth, S. J. Bennett, J. L. Best, and S. J. Mclelland, editors. Coherent flow structures in open channels. Wiley, Chichester, UK.

Smith, D. L. 2003. The shear flow environment of juvenile salmonids. University of Idaho, Moscow.
Smith, D. L., and E. L. Brannon. 2007. Influence of cover on mean column hydraulic characteristics in small poolriffle morphology streams. River Research and Applications 23:125-139.

Smith, D. L., E. L. Brannon, and M. Odeh. 2005. Response of juvenile rainbow trout to turbulence produced by prismatoidal shapes. Transactions of the American Fisheries Society 134:741-753.

Smith, D. L., E. L. Brannon, B. Shafii, and M. Odeh. 2006. Use of the average and fluctuating velocity components for estimation of volitional rainbow trout density. Transactions of the American Fisheries Society 135:431-441.

Valdimarsson, S. K., N. B. Metcalfe, J. E. Thorpe, and F. A. Huntingford. 1997. Seasonal changes in sheltering: effect of light and temperature on diel activity in juvenile salmon. Animal Behaviour 54:1405-1412. 